\title{
The Presumption of Sociality: Social Learning in Diverse Contexts in Brown-Headed Cowbirds (Molothrus ater)
}

\author{
Andrew P. King, Meredith J. West, and David J. White \\ Indiana University Bloomington
}

\begin{abstract}
Data are presented on social and vocal learning in cowbirds (Molothrus ater) housed in large aviaries and given more degrees of freedom than in conventional experimental studies. The studies show that social and vocal outcomes are facultative responses to social contexts. Several findings are reviewed: First, cowbirds quickly self-organize into groups by age and sex; second, opportunities to interact across age and sex do exist and affect courtship competence; third, female cowbirds organize themselves differently in the presence and absence of male competition; and fourth, young, naive cowbirds show rapid and differential sensitivity to group dynamics. Taken as a whole, the data show that social Umwelten are dynamic, developmental ecologies.
\end{abstract}

Solitude is a human presumption. Every quiet step is thunder to beetle life underfoot, a tug of impalpable thread on the web pulling the mate to mate and predator to prey, a beginning or an end. Every choice is a new beginning for the chosen.

-Barbara Kingsolver, Prodigal Summer

Terra firma provides humans with sure footing but sometimes narrow thinking about the sensory world of other inhabitants. The air-ground complex is one of myriad environments, many neither terra nor firma. Navigating and exploring underwater or underground as many animals do has also been intimidating for humans but is now yielding to newer technology and the continued persistence of those humans convinced of the value of knowing other worlds.

Our goal here is to examine a broader contextual concept: How does a social world fit with a self-world? Is a social world merely the sum of self-worlds? Although most scientists agree that animals' sensory systems can be profitably analyzed by looking at animals one by one, scientists show less consensus that animals' perceptual systems, that is, how animals explore, respond, and categorize their sensory worlds, are uninfluenced by animals around them (Gibson, 1966). We propose that the social context matters even at basic levels of sensation and perception: Animals perceive compounded arrays of stimulation, and the salience of the

Andrew P, King, Meredith J. West, and David J. White, Department of Psychology, Indiana University Bloomington.

We thank the Howard Hughes Foundation, the Indiana University Department of Psychology, the Animal Behavior Program at the National Science Foundation, the Research Experience for Undergraduates Program at the National Science Foundation, and the National Science and Engineering Research Council for funding. We thank the Animal Behavior Graduate Group at the University of California, Davis, and Peter Marler for supporting the conference. The experimental work was reviewed by Federal Permit 767781 and relevant Institutional Animal Care and Use protocols. Anne Smith and Shan Duncan supplied valued criticism.

. Correspondence concerning this article should be addressed to Andrew P. King, Department of Psychology, Indiana University Bloomington, 1101 East Tenth Street, Bloomington, Indiana 47405. E-mail: apking indiana.edu parts depends on what else the animal is experiencing. To introduce our ideas means starting where Von Uexkull and other ethologists began, attempting to describe the compounded experiences animals may see, hear, smell, touch, taste, and feel (Von Uexkull, 1934/1957).But in this article, we address sensory pickup of social stimulation. A cross-modal dimension we stress is proximity, that is, being near to another animal. For example, the "sensation" dimension to which we refer is not seismic, as it might be for a rodent underground, but is the proximal "sense" of an animal close to you, say, a few centimeters as opposed to a few meters. Think of someone sitting too close on an airplane. Which senses are affected? Scientiststalk and measure proximity seeking and avoidance, but what of the prior state of proximity sensing? As a statement of its basic value, consider that some of the most venerable ideas in behavior circle around but reliably boomerang back to approach-avoidance as a basic rule (Schneirla, 1957).

In this review, we recount the steps we are taking toward creating a new framework for the study of social Umwelten in birds. As this is only a beginning, we keep a strong focus on the initial stages involved in breaking away from conventional methods and ideas. By characterizing the pathway as paradigmatic, however, we hope to communicate that we would not be describing any of the enterprise if it did not already seem promising. One contribution of Von Uexkull (1934/1957) is especially enlightening: his advice on studying what is familiar to the organism and the corollary need for focus on an animal's home, territory, and companions when discerning Umwelten. He noted that the tendency of psychologists to begin studies by stripping animals of familiarity, including homes and companions, was not the best way to examine a self-defined world.

For most of this article, we focus on brown-headed cowbirds (Molothrus ater), as they have been the subjects of our new (and old) approaches, but we believe the methods described should be useful elsewhere. Given that King and West and colleagues have been studying cowbirds for over 2 decades, people might ask what new methods are left. The laboratory has carried out observational studies, audio playbacks to females, multilayered song analyses, mate choice tests, tutoring, cultural transmission, video analyses of social interactions, hand rearing, bilingual housing, neurobiologi- 
cal analyses, and geographic comparisons. But in our minds, something was still missing: a way to see the birds develop behavior in a rich, social setting allowing them to exploit more degrees of freedom. We were influenced and encouraged by the work of Beecher (1996), who had compared wild and lab-housed song sparrows, Melospiza melodia, and showed differences in the outcomes of tutoring depending on context. In particular, Beecher pointed to the constraints on proximity on the lab-housed birds due to the nondynamic nature of the setting. The young birds' activities could not change their distance to tutors, the young birds had little control over how long they could interact with a tutor, and they could not change the order of tutor presentation.

What would birds learn by themselves if we placed social groups in large aviaries and allowed them to indicate social variables of interest by their proximity? Would song copying or patterns of social dominance change? If young males did not seek out older males, for example, conventional ideas about social tutoring would have to be reevaluated - that is, there might be a preliminary stage, during which young birds must learn not only to attend to adults but to do so with appropriate social contact (i.e., not too close, not too far). The results of different social experiences might also be stored differently in memory. So, too, if adult females ignored young males in open contexts, if they eliminated proximity as a variable, the source of social influence found in earlier work (Smith, King, \& West, 2000) would have to be rethought. Thus, to carry out the new work, we created more socially complex settings, large indoor-outdoor aviaries, in which the animals can have more control over social distance (see Figure 1). The shorthand name for the design is the ad-lib context: Give the birds space and options and measure what happens.

In the sections to follow, we describe in more detail the results of the transition of the lab to aviary settings. We then describe several studies that used the new plan and why we believe it has implications for defining sensory and perceptual worlds.

\section{Breaking Away: Do Cowbirds FormGroups?}

In the jargon of the lab, the ad-lib paradigm is labeled simply by the size of the flocks of birds used: the big flock (Smith, King, \& West, 2002), the four little flocks (White, King, \& West, in press-a), and the five summer flocks (White, King, Cole, \&West, 2002). The common theme of all of the studies is that the animals live together, ranging in group size from 25 to 75 cowbirds. In nature, groups often live in much larger roosts, but during the day, they break off into small groups of sizes comparable with those in our aviaries (Friedmann, 1929; West \& King, 1980).
When we conceived of the paradigm, we were motivated by two concerns. First, we wanted to explore systematically the role of intrinsic, self-regulated activity in modifying and shaping social and vocal experiences, the concerns noted by Beecher (1996) earlier. Second, we wanted to create an experimentally sound and functionally robust framework to hold all of the individual pieces of evidence we were accumulating on social learning; that is, we wanted to be able to watch juveniles from their first fall to their first breeding season to map trajectories of courtship competence.

Our interest in birds' self-regulation of their social ecology stemmed from our conclusion that the conditions used in the past did not exploit the variable of self-regulation. Thus, we put the birds explicitly in charge of creating their own early or late experiences and their own degree of participation. So, too, we limited our role to that of measuring whatever it was the birds chose to do, hoping to find patterns that would lead to organizing principles for explaining learning and variation. In all of our work, as in most work with any organism, a range of outcomes occurs, from modal species-typical acts to seemingly anomalous outliers. But would more vigilance on our part give more insight into why such norms of reaction occur?

Our second objective, finding a better functional framework, reflects our recognition that we did not need any more evidence of malleability in cowbirds; rather, we needed evidence of how cowbirds naturally put together the. many experiences during their first year into a coherent outcome. This need was increasing, because the more we learned about male cowbirds, the more piecemeal the birds' knowledge seemed to be; that is, they seemed to have to learn many details and were not endowed with any big picture. The most striking data came from male cowbirds that had been housed with pairs of canaries (Serinus canaria) from late August until May. Afterward, when the breeding season came, they sang and chased the canaries, flyingright by female cowbirds. How could mate recognition be so fragile? These birds had originally been wild-caught with other cowbirds; they "knew" their species. Furthermore, how could mate recognition be so unstable in a brood parasite? Cowbirds are raised by over 200 different species and subspecies; if any species should be selected for a closed program of mate recognition, it would seem to be the cowbird, so as to avoid mistakes as well as ensure appropriate recognition (Freeberg, King, \& West, 1995; King, West, \& Freeberg, 1996; West, King, \& Freeberg, 1996).

In addition, and just as unsettling theoretically, juvenile male cowbirds given conspecific experience in sound-attenuatingchambers with adult females developed poor social skills. For example, we found that juvenile male cowbirds that were housed all winter

Figure I (opposite). Three views of the ad-lib aviary. (A): A two-dimensional floor plan to scale of four aviaries, which were interconnected for Smith et al. (2002) and used separately in other reported work. The objects within the aviary complex include feeding stations (denoted by four scalloped squares), trees (represented as irregular circles), four observation decks (denoted by dark rectangles), and staircases (represented by four striped squares). T wo people could sit comfortably on the observation decks. Interior shelters are denoted as gray rectangles, and interior observation areas, by stippled texture. (B): A three-dimensional layout of the same facility as viewed from $25 \mathrm{~m}$ away and $10 \mathrm{~m}$ above the complex. Note the translucent roofs over the interior shelters. The tree in the foreground is $\mathbf{2} \mathrm{m}$ tall. (C) and (D): Two views within one of the aviaries, showing the typical amount of foliage during the late spring and summer and fall. 
(A)

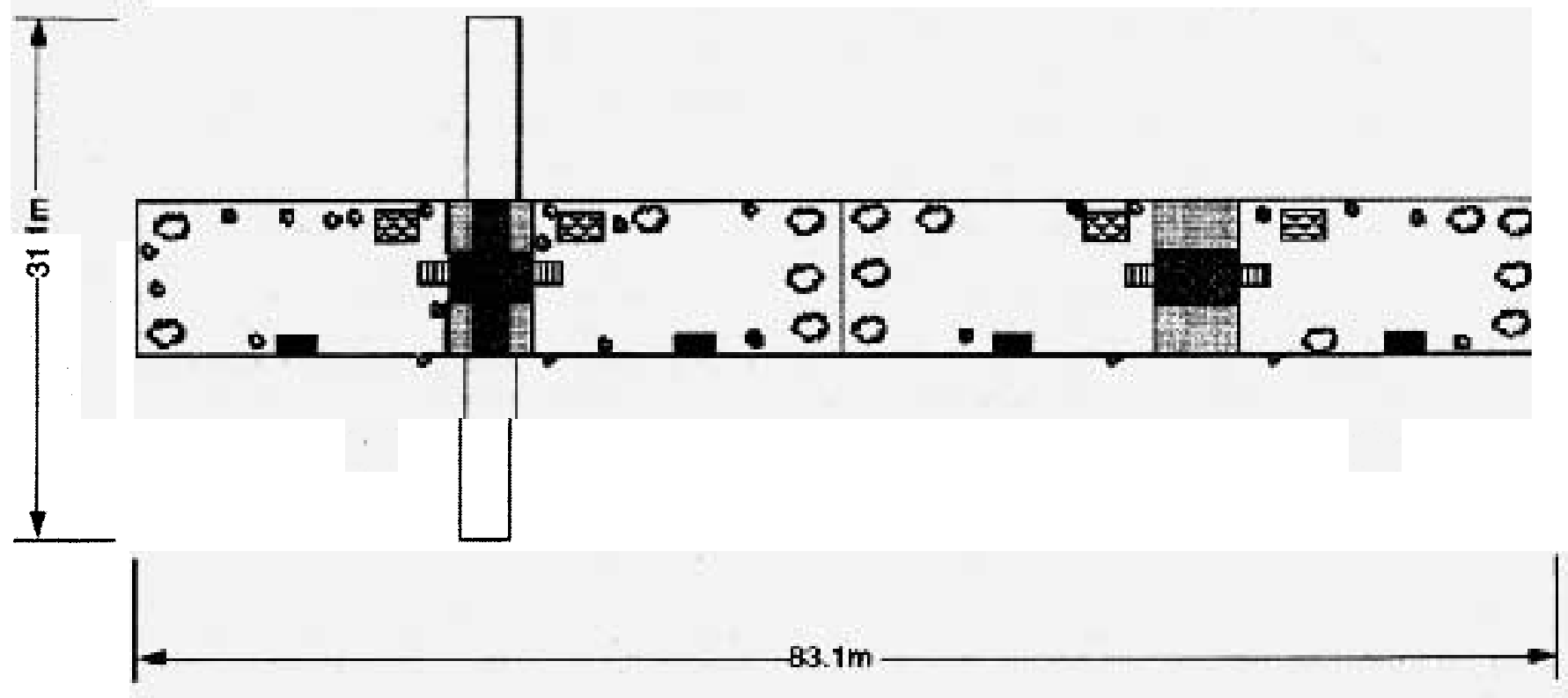

(日)

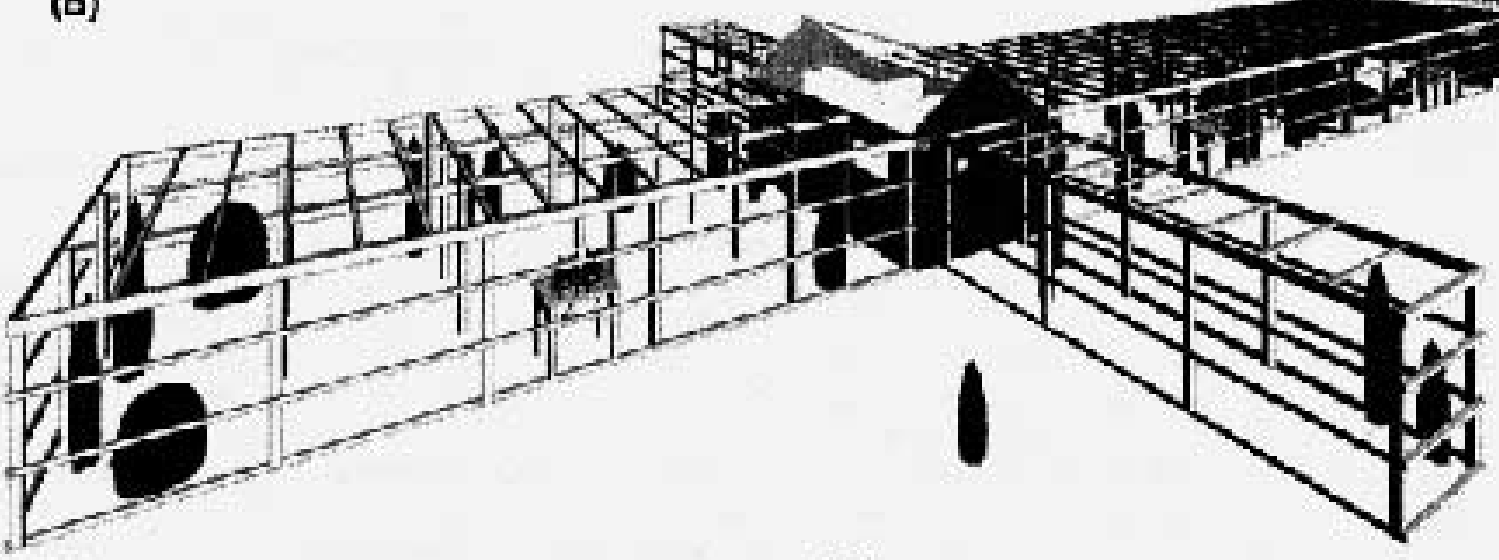

(C)

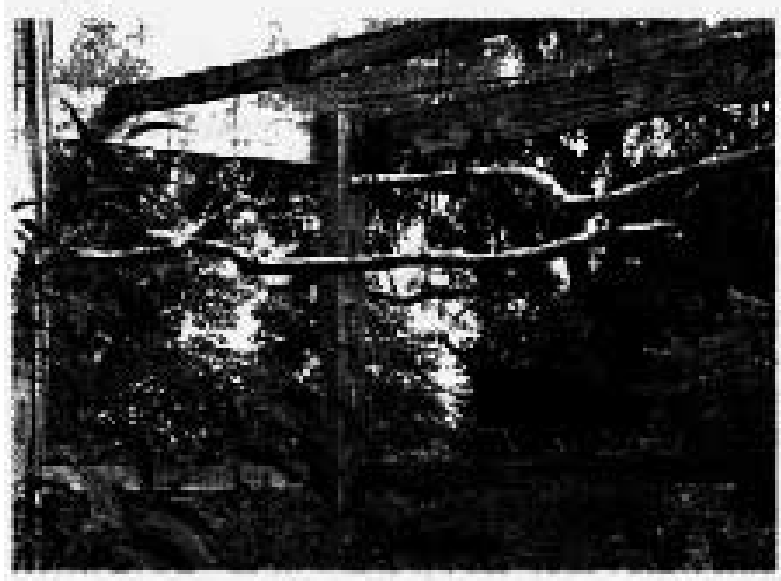

(D)

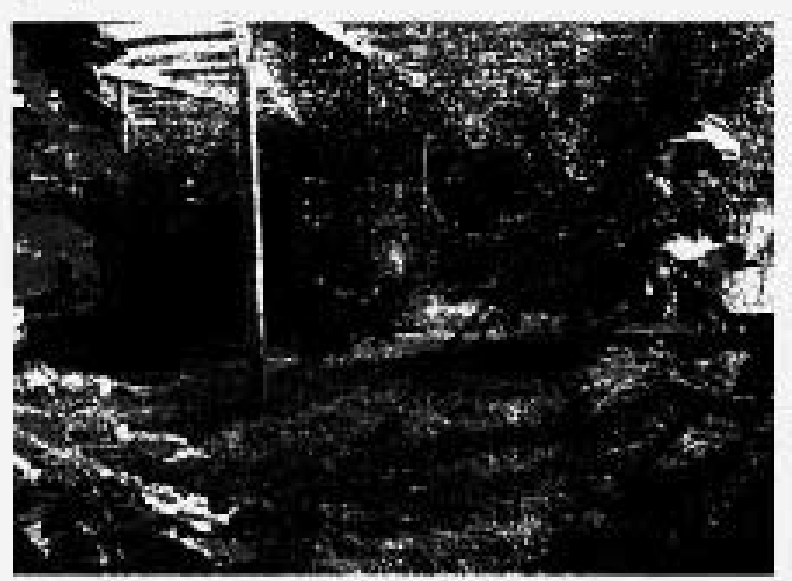


with females did not necessarily show much interest in using their song to court females in the breeding season (West, King, \& White, in press). In these longitudinal studies, we discovered a glaring disconnect between capacity and performance: male cowbirds with potent songs, as measured by playback and song analysis in the laboratory, apparently did not know how to use them when placed in the functional context of mate competition, even when the only competition was other young males like themselves. When faced with the "real thing," the males generally ignored females, singing instead to one another. These data suggested males could not or would not use what they had learned in a more simplified setting in the fall and winter where females could not effectively get away from males and where males may have assumed that a female would always be available when he was ready to sing (West, King, \& Freeberg, 1997).

The males' incompetence was especially surprising because their interactions with females had initially appeared to have beneficial effects. The female-housed males' rate of vocalizing correlated with faster progress through the stages of song development and resulted in the production of song highly effective at eliciting copulatory responses, when recorded and played back to new female cowbirds (Smith et al., 2000). In those studies, however, the young males had little choice but to receive female feedback when they sang, as they were living in 1.3-m3 soundattenuating chambers with two female conspecifics. In such close quarters, perhaps males did not learn that a female must be strategically approached and that she is very unlikely to come to him. But the idea that cowbirds had to learn so basic a skill as achieving proximity to a conspecific was surprising. Was it possible that cowbirds, as brood parasites, have a lot of ontogenetic catching up to do? After all, they have already completed one life as an unwitting impostor; maybe they start their second life with an additional layer of naivete as they regroup to interact with their own kind.

The disconnectedness that characterized the young males' behavior suggested another possibility. Perhaps the restricted social setting itself fostered fragmentary learning. Although many young songbirds have been raised in restricted social environments, there are few data on any subject but their song. Most observations about nonsong behavior remain unpublished but suggest that birds housed in isolation emerge showing signs of nervousness and agitation. In the past, song researchers rarely pursued the social consequences of deprivation housing, as it was not part of their agenda. Their interest was how song develops and is maintained across generations, and isolated birds do sing. In such a paradigm, a song was legitimately seen as a separable behavioral part to be studied without the bird evenbeing present - and without question, behavioral parts, as opposed to whole animals, are popular during these reductionistic days. Across the life sciences, the focus on parts is the sine qua non of modem science; it is the means by which integration is achieved across levels.

Thus, as we thought about our incompetent birds and their too easily separable skills, it seemed more and more likely that our methods were reinforcing behavioral and theoretical compartmentalization. Social aviaries were our way to counter this bias, to give multiple animals multiple options. By placing all of our birds in one large basket, as it were, we anticipated that more of the behavioral parts, the fragmented abilities, could be viewed at the same time in the same setting.
We should emphasize that we did not think of these more complex environmentsas ecological analogues for the species, but at least they qualified as social ecologies, affording an opportunity to measure animals in social groups given considerable degrees of freedom as to how they used their environment. Before we turn to the flock experiments that illustrate the ad-lib dynamics, we should emphasize that as we began the shift to more complex ecologies, we did have a path to follow. Freeberg (1996) had studied the ontogeny of mate choice in our laboratory. He had avoided the inevitable social compartmentalization of most studies of song learning by virtue of his housing conditions, to be explained shortly. Freeberg's interest was cultural transmission of courtship skills in cowbirds: Could young birds be "taught" through exposure to an unfamiliar population of cowbirds to alter mating preferences? Furthermore, would these birds pass on any acquired preferences to a new generation (Freeberg, 1996, 1997, 1998)?

In his work, Freeberg (1996) took whole animals and developmental ecology seriously. He gave his birds choices. All of the birds lived in large aviaries (see Figure 1) where they could interact with other juvenile birds from the original population and adults of one of the two experimental populations. The first experimental adult population was composed of birds from the same geographic area as the juveniles; the other population was from $1,500 \mathrm{~km}$ away. The young birds, male and female pupils, were randomly assigned to these conditions after having been wildcaught with other cowbirds from their natal area. Thus, there was no targeted "tutor"; all of the adults were potential models, and from the young birds' point of view, their juvenile peers were also sources of instruction.

But the cowbirds responded well to the added social complexity and produced reliable and orderly data showing that the experimental adult cultures were transmitted, meaning experimental birds "lost" their natal preference. The cultural effects included mate preferences and the contents of songs. To obtain the outcome, the female cowbirds had to change along with the males, as female choice is apparent in this species in the wild and was seen in these birds.

The change in female preference was the most striking from the point of view of the history of the lab's work. With one exception, no way had been found to show that female cowbirds altered their natal preference even if they were hand-reared and exposed only to males from a distant population. All of the attempts were based on the premise that perceptual modifications would be most likely to come about by removing birds from their normal culture, hopefully biasing them toward a new culture. According to this reasoning, if a female cowbird from South Dakota hears onl y songs from Indiana males, she will either forget or reformulate her song preferences. But that had never happened when females were housed individually with males (King \&West, 1990). Thus, when the females in Freeberg's $(1996 ; 1997)$ work showed plasticity, the importance of a social group became even more significant. It was the Kuhnian anomaly needed to provoke action.

\section{The Aviary as Classroom}

For the purposes of this review, we have chosen to focus on questions that relate to work done previously in more restrictive settings to compare the kinds of knowledge obtained in ad-lib settings. The first question concerned juvenile male competence. 
For example, previous work with juvenile males housed with female cowbirds and no adult males suggested that they could develop good songs but did not know how to use them in speciestypical ways when asked to compete for mates (West, King, \& Freeberg, 1996). Thus, we wondered how juvenile males in an ad-lib setting would fare when given much richer stimulation but when some were still deprived of adult male companions. The second question focused on females. Freeberg's (1996) work suggested that females were sensitive to their social setting. Could we elicit signs of such sensitivity if females lived in groups with or without males and with or without juvenile males? We were examining not whether we could change their song preferences but whether different social contexts changed them in ways that could illuminate Freeberg's work. We also looked at adult male malleability: Did different demands for interactions with juvenile males affect males with already established song and courtship repertoires?

The overarching question was in some ways the most basic. Could we use the ad-lib design to show social sensitivity at a flock level? That is, could we find evidence of what constituted a group as opposed to a collection of individuals? This question came closest in our minds to reexamining what is meant by "an animal in the context of its environment." Could we show that the same general environment was composed of different proximate contexts for different individuals?

The specific nature of the ad lib setting is central tothe studies to be described (see Figure 1). In the first study, we housed $\mathbf{7 4}$ wild-caught adult and juvenile male and female cowbirds (roughly equally divided into the four classes) together in a spacious aviary complex large enough so that birds at opposite ends were socially and acoustically separated. As a way of calibrating the difference in social space between this and previous experiments, we measured the cubic space available per individual bird. Our soundattenuation chambers have a volume of $1.3 \mathrm{~m}^{3}$, providing 3 birds with $0.4 \mathrm{~m}^{3}$ per bird (as in Freeberg et al., 1995; Smith et al., 2000). The aviary complex used in this study has a volume of $2,516.0 \mathrm{~m}^{3}$, giving our 74 birds each $34.0 \mathrm{~m}^{3}$, over 85 times the volume available per bird in a sound-attenuationchamber. Figure 1 provides several representations of what these differences mean. By allowing unconstrained movement throughout the complex, we hoped to achieve a seminatural approximation of an over-winter group, where behavioral interactions between individuals are less affected by spatial constraints.

The aviary complex offered many behavioral options. There were multiple feeding stations and shelters, abundant shrubbery and trees for perching and congregating, and natural sources of food, such as insects and grains on the ground. Predators - mainly hawks, but some owls and raccoons (Procyon lotor)--occasionally patrolled the aviaries, providing distractions and different social contexts for acts such as alarm reactions. Moreover, there were wild birds outside the aviary, including a few local cowbirds (but never more than a handful at any point in time).

The difference between living in an aviary with many other individuals and living in a small enclosure with one or two birds had many consequences, but of particular interest were the bioacoustic implications for the male cowbird's song, as it is critical to female assessment of mates. The female-salient elements of male cowbird song degrade rapidly at distances beyond a third of a meter (King, West, Eastzer, \& Staddon, 1981). Males living in a 10-m3 chamber were unable to sing without having a clear rendi- tion of their song available to their social companions, and their companions had no way to leave the area of singing. But even in such controlled circumstances, proximity mattered: Males with females that permitted males to sing at close distances developed more effective songs than males housed with females that flew away to song overtures (Smith et al., 2000). In a larger aviary, the females had even more social options, raising the question of whether females would associate closely enough with the juveniles to hear the female-salient elements of the song at all. The male cowbird's other main vocalization, the flight whistle, could be heard throughout the aviary and often served as an alarm call when hawks or new humans approached.

The bioacoustics of the ad-lib aviary had implications for interactions with other males as well. In a previous study during the breeding season, we found that adult males attacked socially naive adults when placed with them for periods as short as $4 \mathrm{hr}$. The naive males sang songs especially stimulating to females but had not also established dominance with other males (West \& King, 1980).Juvenile males may need to separate themselves from adult males while practicing song to avoid stimulating aggressive responses.

All of these considerations converge on the role of social proximity. To capture this dimension, all of the flock studies used as a central measure the spatial relations of juvenile males with adult males and females. In many species, near-neighbor association measures are considered useful measures of social organization, and in primates, patterns of proximity represent a perhaps subtle form of competition. With respect to social organization, we needed a way to judge whether the 74 birds showed any signs of stable group behavior or whether the associations were simply random patterns of movement.

We also reasoned that spatial proximity afforded access of social information from conspecifics and promoted opportunities to engage in interaction (Coussi-Korbel \& Fragaszy, 1995; Freeberg, 1999; Holekamp et al., 1997). Near-neighbor measures have been used in this manner in birds, ungulates, and primates (Boinski \& Mitchell, 1994; Bon, Rideau, Villaret, \& Joachim, 2001; Wynne-Edwards, 1962). Birds within a near-neighbor zone (30.0 $\mathrm{cm})$ can also hear the female-salient elements of song with high fidelity (King et al. 1981). Although it does not necessarily follow that an individual interacts with all birds that are near neighbors, the nature of these associations provide a social overview of flock dynamics. In addition to near-neighbor assessments, we also recorded singing behavior of adult and juvenile males over the year and measured their courtship success at the end of the experiment. We focused specifically on juvenile males, in light of our past work suggesting they had much to learn to become socially competent. Given a broad range of possible companions and given the ability to separate spatially, what would juvenile males do?

As might be imagined, data collection from 74 birds in a football-field-length landscape is challenging. As the work has progressed, so have our procedures for capturing the most behavior possible, evolving from pencil-and-paper records into voicerecognition protocols to maximize speed and efficiency of data collection and minimize looking away from the birds (White, King, \& Duncan, 2002). The strategy was to census the birds and record any near neighbors, that is, a bird within $30 \mathrm{~cm}$ of another bird with no obstruction (e.g., a tree branch) between them. Data were collected in fall, winter, and spring. During a 10-min data 
block, the observer chose target birds by scanning the aviary and picking birds with at least one near neighbor. The near neighbor of the target was recorded. A pair of birds was sampled only once during a session. A song point was scored for a male the first time he sang during the 10 -min period. Only one song point could be taken for each male during the data block.

Over the entire year, observers recorded 26,833 near-neighbor points and 7,502 song points during 1,576 data blocks, for a total of $263 \mathrm{hr}$ of data (577 data blocks in fall, 464 in winter, and 535 in spring). Of the 163 days spanned by the three sampling periods, data were collected on 136 days (we watched the birds on average 6 days a week; range $=3-7$ ). We also recorded the birds' vocal repertoires.

Near-neighbor measures differed somewhat by season, although at all times, assortment was greatest by sex and less so by age. During the breeding season, near-neighbor measures seemed less relevant given how much the birds moved around in the morning while courting. Smith (2001), using microsatellite DNA analyses, also looked at possible kin-related assortment for all the birds and found no evidence that relatedness affected assortment. Smith found little evidence of relatedness at all within the flocks, even though all birds were collected at the same site. A previous report had suggested that adult females are found in association with their young when they are fledglings, but Smith's data did not replicate this finding (Hahn \& Fleischer, 1995).

Here, we focus on several measures. First, we wanted to find out whether the birds' natural gregariousness translated into social organization. It did. Nonrandom patterns of association emerged in the group of freely assorting birds. A general pattern of Age X Sex association rapidly occurred across all four age and sex classes. Said another way, birds accumulated the most near-neighbor points per bird with others of their own age and sex, next most with birds of the same sex but different age, less with those of different sex but same age, and least with birds of the opposite age and sex class (see Figure 2).

This result was not surprising, as Freeberg (1999) had seen similar social tendencies in his work. But the rapidity with which the organization appeared and its general stability were noteworthy. Within 6 days of introduction to the aviary complex, we saw the pattern of birds differentially associating with one another at statistically significantlevels (Smith, 2001). Regardless of how we divided the data, by season, by time of day, by number of days, or by observer, the result was the same, the cowbirds settled into

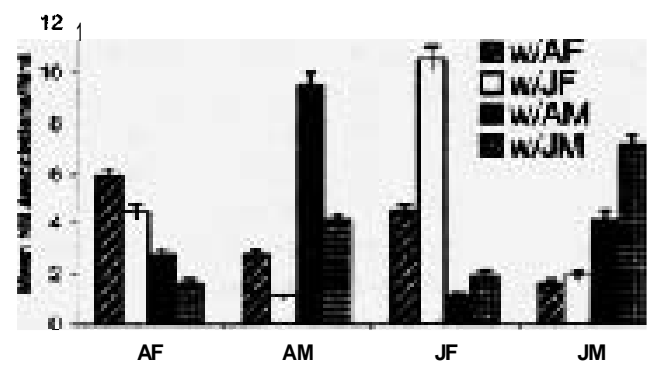

Figure 2. Mean proportion and standard error of near-neighbor (NN) associations for birds of each sex and age class in the big flock experiment. $\mathbf{A F}=$ adult females; $\mathbf{J F}=$ juvenile females; $\mathbf{A M}=$ adult males; $\mathbf{J M}=$ juvenile males.
Age $x$ Sex assortment. Although there was some shifting especially between adult and juvenile males across the sampling periods, there appeared to be a social rule at work guiding individuals toward a nonrandom set of individuals within the aviary. But for all classes, there was cross-assortment, just at a lower level of frequency. It thus appeared the birds operated from the relatively secure base of Age $X$ Sex groups, making excursions into other classes. For example, in the fall, adult males assorted less with juvenile males than did adult females with juvenile females. In winter, adult males associated more with juvenile males than they had earlier. Most striking, in fall and winter, adult females associated relatively often with juvenile males. Smith (2001) also found that beyond the level of near neighbors, there were also different groups of singing neighbors (birds within 60.0 vs. 30.0 $\mathrm{cm}$ ); thus, birds congregated differently depending on what they were doing. And it was in these singing contexts that the most contact occurred between juvenile males and adult females.

Did these over-wintering patterns make any difference? We looked at the courtship success of juvenile males when they were competing against otherjuveniles for an answer. Courtship success of juvenile males was correlated with individual differences in association with adult males over the year. Juvenile males that associated more with adult males developed consortships with females faster than males with lower adult association scores.

The singing rate of juvenile males was also affected by choice of social partners. In experiments in restrictive enclosures, we found that juvenile males housed with local, compatible females developed mature song sooner, which was also correlated with a decrease in singing rate, perhaps because the birds needed less practice. In the ad-lib context, juvenile males that associated most with females sang less over the year, perhaps because the feedback they received also advanced the rate of transition through song stages. Juvenile males also developed more original songs. We need more data on this point, but again, the data show that differential assortment appears to have differential social effects. We also recognize that teasing apart the direction of effects is critical. As yet, we do not know whether certain adult males or females initiate such interactions or simply tolerate them differently. It is also possible that assigning such active or passive roles in a dynamic setting will not be easy.

The results of the ad-lib aviary experiment revealed to us that the new paradigm had potential for success. We could still investigate social behavior systematically, and we were getting results; we now had correlations suggesting that Social settings influenced developmental trajectories of functionally important behaviors. The next step was to design experiments to test these correlations.

We hypothesized that if social organization affects options for obtaining experience, then individuals living in groups favoring different organization should display different developmental outcomes. To test this idea, we set up four aviaries with four groups of birds. All groups contained juvenile and adult females, but the age class of males present differed. One group had both adult and juvenile males, one had only juvenile males without adults, one group had only adult males without juveniles, and one group did not have any males at all. Each group contained approximately 24 birds. We observed the groups daily from September until the breeding season. The results continued the theme of emergent organization: The aviaries developed different social patterns, which affected later outcomes for individuals living in those con- 
texts. Each aviary presented a different near-neighbor social profile, along with reliable differences in social interactions. Briefly, for any group of birds - juvenile males, juvenile females, adult females, and even adult males - the self-created social environment in which they lived produced different behavior patterns.

Juvenile males, differing only in experience with adult males, developed considerably different courtship and communicative skills. Prior to the breeding season, juvenile males housed with adults generally chose other juvenile males as near neighbors but frequently sang to other males and to females. In the breeding season, these males were aggressive with other males and courted and copulated with females in patterns typical for cowbirds in the Midwest. In great contrast, juvenile males housed with no adult males displayed less social organization at any time during the year. They attended little to females and sang in long bouts of undirected soliloquies throughout the year (see Figure 3). In the breeding season they showed no aggression toward other males and showed little selectivity in singing to (see Figure 4), courting, or even copulating with individual females. Juveniles housed with and without adults also developed structurally different songs at different rates, with juveniles housed without adult males advancing sooner to stereotyped song and developing song more effective at eliciting females' copulatory responses than juveniles housed with adult males. The large number of atypical behaviors exhibited by the juveniles housed without adults suggested to us that juvenile males required interactive contact with adult males to develop species-typical courtship abilities (White, King, \&West, in press-a).

Females in the large aviaries had the space to meter their social distance with males and with other females. Females took advantage of this opportunity differently across the different conditions. Across conditions, males engaged in different levels of intersexual assortment and interaction (see Figure 5). Females' assortment with males varied with the nature of the males' intrasexual social interactions across conditions (see Figure 6). In the all-adult male condition, females affiliated with males far more than did the females in the other two conditions that contained males. In the all-juvenile male condition, females stayed with the other females, rarely approaching juvenile males. Furthermore, when no males were present, females shifted their assortment pattern again, this time showing no assortment by age at all.

In the breeding season, the females from the different aviaries differed in the number and pattern of their copulations, their egg produetion, and their egg-laying behavior. Females housed with only juvenile males laid fewer eggs and destroyed more of them than did females housed with adults. Thus, there were multiple

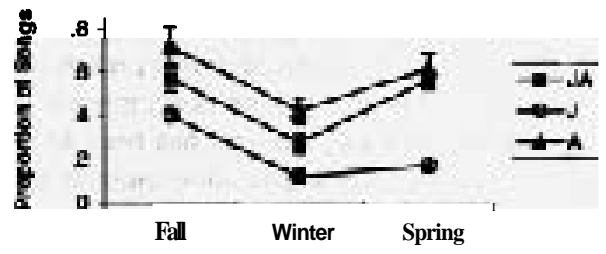

Figure 3. Mean proportion and standard error of total song that was directed for males in the juvenile-adult (JA), juvenile (J), and adult (A) conditions for three sampling sessions before the breeding season in the four little flocks experiment.

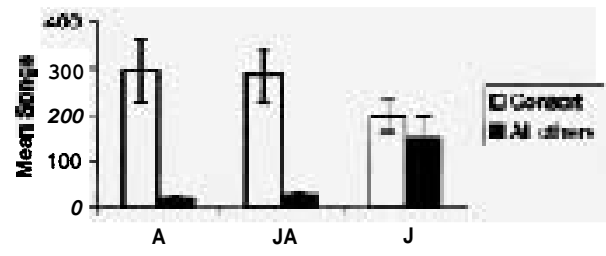

Figure 4. Mean number and standard error of songs sung to females by their consort male and by all other males in aviary in the adult (A), juvenile-adult (JA), and juvenile $(\mathrm{J})$ conditions during the breeding season in the four little flocks experiment.

signs of female sensitivity to social context, with an important variable appearing to arise from the nature and tenor-aggressive or nonaggressive - of male-male interactions (West, White, \& King, in press).

It is generally considered the case that there is little or less vocal or social modifiability in adulthood in cowbirds and many songbirds. But it is also the case that adults have not been studied in as much detail. For most of the year in the flocks, this assumption held true; there were few differences between the two groups of adult males (adult males housed either with or without juvenile males). Both groups sang approximately the same amount, although adults in the all-adult condition did sing more songs over the year to females, who in turn, spent more time close to the adult males. It was thus quite a surprise when we compared the two adult groups during the breeding season. We brought the two groups of adult males together in a new aviary, allowing them to compete directly against each other with a new group of females. Here, a difference among adult males from the two groups became abundantly obvious. The adult males housed over the year with juvenile males vastly outcompeted adult males housed without juveniles. Every single adult male formerly housed with juveniles got copulations faster than males housed with peers. In fact, only one of the adult males housed with peers managed to get any copulations at all. We assume that the dynamics of interactions with juvenile males contributed to these differences. Throughout the year, juvenile males explored their physical and social environments, even though they did not know the rules of social interaction. Thus, the juveniles may have inadvertently involved adult males in frequent social challenges. These interactions may then have translated into reinforcing the competitive abilities of adult males, whereas the adults with no juveniles lived in a stable social environment and

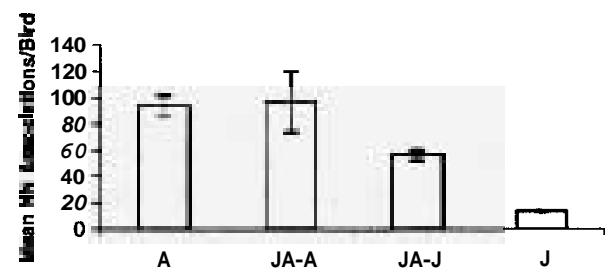

Figure 5. Mean male-male near-neighbor (NN) associations per male and standard error for males in the all-adultmale (A), all-juvenile male (J), and juvenile-and-adultmale (JA) conditions before the breeding season in the four little flocks experiment. Associations in the condition in which both age classes of males are present are divided into associations for juvenile males (JA-J) and adult males (JA-A). 


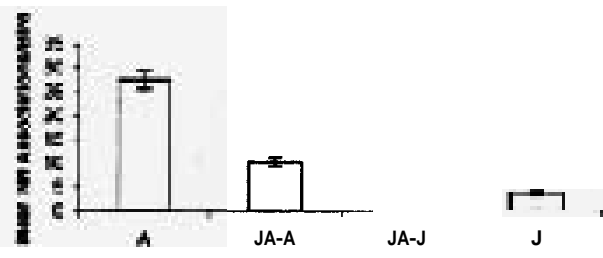

Figure 6. Mean male-female near-neighbor $(\mathrm{NN})$ associations per male and standard error for males in the all-adult male (A), all-juvenilemale (J), and juvenile-and-adult male (JA) conditions before the breeding season in the four little flocks experiment. Associations in the condition in which both age classes of males are present are divided into associations for juvenile males (JA-J) and adult males (JA-A).

were not experienced in dealing with and reacting to changing social stimulation (White, King, \& West, in press-b).

Recently, we also studied the influence of adults on social organization of very young cowbirds. We housed juvenile birds, caught in the first few days of independence from their host nest, in aviaries that either contained or did not contain adult conspecifics. We then observed juveniles' social associations and song in each. The presence of adults in the social environment influenced juveniles' assortment and singing patterns even though throughout the experiment adults rarely interacted with the juveniles with which they were housed. Juveniles housed with adults interacted with other juveniles more often and sang significantly less than juveniles housed without adults. Effects of adult presence or absence on social organization and singing patterns emerged extremely rapidly and could be reversed quickly. The most dramatic factor in this experiment was that the two conditions were in adjacent aviaries separated by only hardware mesh. Thus, the birds in the two conditions could see, hear, and associate near each other. Yet this made no difference. Even though the two groups were next to each other, they were social worlds apart. Their attention, perception, and motivation were all tuned to their own group. Furthermore, differences in organization in the two groups produced very different social environments, affording different gateways for social learning and vocal development (White et al., 2002).

Taken as a whole, these data tell us that the nature of cowbird development is facultative - that is, social or vocal development is neither a fixed nor a centralized program. It is assembled on-line from recurring interactions with others in the social environment. Each of the social environments influenced the birds in the study. Birds engaged in the behaviors that were successful within their group, an effect we have since replicated four times with juvenile males and two times with adults (West, White, \& King, in press). The characteristics associated with mating success in one social environment were not the characteristics of success in another social setting, nor was the success of an individual in one environment predictive of that individual's success in another. In sum, social context matters. Its impact was apparent everywhere, obscuring the interpretations of some of the well-known traditional rules of animal behavior - for example, song potency's correlation with mating success, intrasexual competition, song learning, female choice, or even the idea of a species-typical mating system. No simple statement about any of these characteristics can be made without reference to social context.

\section{Summary: Is a Complex Aviary a Complex System?}

Behavior and its ontogeny constitute a complex system, as the term is formally used in the vocabulary of adaptive systems and complexity theory. A fundamental finding of such research is the imbalance between effects on the behavior of an excised part and the system from which it was excised (Bar-Yam, 1997). The greatest effect is on that which is removed and not on the system from which it was removed (e.g., think of cutting a leaf from a plant or taking a single worker ant from a colony). Isolating songbirds from the social system in which they normally live and from social environments to which they are adapted may have produced the same imbalance and led to distortion in theories by reducing the chances that one could see social effects. What do the ad-lib aviaries tell us by using a less restrictive approach?

First, they offer many confirmations of the social effects we had found in much simpler environments. Juvenile male cowbirds are sensitive to social influences from males and females, and vocal and social outcomes cannot be predicted without knowledge of their ontogenetic social context. This is not that surprising: Animals have no off-the-shelf phenotype for aviary or field but rather have a range of behaviors, with different probabilistic relationships to the environment providing reinforcement (Timberlake \& Silva, 1994). What is new in the ad lib studies is that we have pushed the learning process several steps backward toward the context surrounding the initial pickup of information, the development of selective attention, and perceptual learning in general (Gibson, 1966).

The ad lib experiments tell us that cowbirds, given the option of familiarity, operate from within proximal social networks: young males with young males, females with females, and so forth. Proximity preferences fall into place early. Thus, when groups or singletons are used in the lab, an ambient and perhaps familiar social structure has been removed. What could such a structure provide? It may provide a stable base from which to explore and calibrate the world. The ad lib aviary might be seen from a bird's point of view as providing waves of variation and stability - the day-in-and-day-out encounters affirming some rules and modifying others; as developmental and environmental parameters introduce changes. Those studying group dynamics in humans and other animals stress that individuals "turn into" groups when they perceive common properties and stability between their own actions and others' (i.e., perceived unity; Forsyth, 1999). Thus, an early task for cowbirds must be figuring out the stable behaviors of each age and sex.

These data as a whole suggest that birds may spend initial time in assessing the tonic stability of a group. The traditional markers of communication, singing or calling, come after this initial period of ecological and group assessment. Moreover, when the animals create the ecology, it is that much more discriminable to them.

Throughout this special issue, the goal has been to learn what senses animals possess and use and to allow animals to show us, as humans, worlds we cannot or choose not to perceive. As can be seen, the effort at any scale brings with it many methodological and theoretical questions. In our case, the questions are focused on a broad social dimension. Hard questions await us as we contend with how sociality affects the flow of information. By giving the birds the presumption of sociality, we hope to open a gate to permit 
us to see their social world, where senses merge in the business of living and learning.

\section{References}

Bar-Yam, Y. (1997). Dynamics of complex systems. New York: Addison Wesley.

Beecher, M. D. (1996). Birdsong learning in the laboratory and field. In D. E. Kroodsma \& E. H. Miller (Eds.), Ecology and evolution of acoustic communication in birds (pp. 61-78). Ithaca, NY: Cornell University Press.

Boinski, S., \& Mitchell, C. L. (1994). Male residence and association patterns in Costa Rican squirrel monkeys (Saimiri oerstedi). Journal of Primatology, 34, 1441-1453.

Bon, R., Rideau, C., Villaret, J.-C., \& Joachim, J. (2001). Segregation is not only a matter of sex in Alpine ibex, Capra ibex. Animal Behaviour, 62, 495-504.

Coussi-Korbel, S., \& Fragaszy, D. M. (1995). On the relations between social dynamics and social learning. Animal Behaviour, 50, 1441-1453.

Forsyth, D. R. (1999). Group dynamics (3rd ed.). Belmont, CA: Brooks/ Cole.

Freeberg, T. M. (1996). Assortative mating in captive cowbirds is predicted by social experience. Animal Behaviour, 52, 1129-1142.

Freeberg, T. M. (1997). Cultural transmission of behaviors facilitating assortative courtship and mating in cowbirds (Molothrus ater). Unpublished doctoral dissertation, Indiana University Bloomington.

Freeberg, T. M. (1998). The cultural transmission of courtship patterns in cowbirds, Molothrus ater. Animal Behaviour, 56, 1063-1073.

Freeberg, T. M. (1999). Spatial associations provide a context for social learning of courtship pattern of brown-headed cowbirds, Molothrus ater. Journal of Comparative Psychology, 113, 327-332.

Freeberg, T. M, King, A. P., \& West, M. J. (1995). Social malleability in cowbirds (Molothrus ater artemisiae): Species and mate recognition in the first 2 years of life. Journal of Comparative Psychology, 109, 357-367.

Friedmann, H. F. (1929). The cowbirds. Springfield, IL: Charles C Thomas.

Gibson, J. J. (1966). The senses considered as perceptual systems. Boston: Houghton Mifflin.

Hahn, D. C., \& Fleischer, R. C. (1995). DNA fingerprint similarity between female and juvenile brown-headed cowbirds trapped together. Animal Behaviour, 49, 1577-1580.

Holekamp, K., Cooper, S. E., Katona, C. I., Berry, N. A., Frank, L. G., \& Smale, L. (1997). Patterns of association among female spotted hyenas (Crocuta crocuta). Journal of Mammalogy, 78, 55-64.

King, A. P., \&West, M.J. (1990). Variation in species-typicalbehavior: A contemporary theme for comparative psychology. In D. A. Dewsbury (Ed.), Contemporary issues in comparative psychology (pp. 331-339). Sunderland, MA: Sinauer.

King, A. P., West, M. J., Eastzer, D. H., \& Staddon, J. E. R. (1981). An experimental investigation of the bioacoustics of cowbird song. Behavioral Ecology and Sociobiology, 9, 211-217.

King, A. P., West, M. J., \& Freeberg, T. M. (1996). Social experience affects the process and outcome of vocal ontogeny in two populations of cowbirds. Joumal of Comparative Psychology, 110, 276-285.
Schneirla, T. C. (1957). The concept of development in comparative psychology. In D. B. Harris (Ed.), The concept of development (pp. 78-108). Minneapolis: University of Minnesota Press.

Smith, V. A. (2001). Social behavior in brown-headed cowbirds: Emergence in a complex system. Unpublished doctoral dissertation, Indiana University Bloomington.

Smith, V. A., King, A. P., \&West, M. J. (2000). A role of her own: Female cowbirds (Molothurs ater) influence male song development. Animal Behaviour, 60, 599-609.

Smith, V. A., King, A. P., \& West, M. J. (2002). Learning in a social context: Affiliation patterns in a captive flock of brown-headed cowbirds (Molothrus ater).Animal Behaviour, 63, 22-35.

Timberlake, W., \& Silva, F. J. (1994). Observation of behavior, inference of function, and the study of learning. Psychonomic Bulletin \& Review, $1,73-88$.

Von Uexkull, J. (1957). A stroll through the world of animals and men: A picture book of invisible worlds. In C. H. Schiller (Ed.), Instinctive behavior: The development of a modem concept (pp. 5-82). New York: International Universities Press. (Original work published 1934)

West, M. J., \& King, A. P. (1980). Enriching cowbird song by social deprivation. Journal of Comparative and Physiological Psychology, 94, 263-270.

West, M. J., King, A. P., \& Freeberg, T. M. (1996). Social malleability in cowbirds: New measures reveal new evidence of plasticity in the Eastern subspecies (Molothrus ater ater). Journal of Comparative Psychology, 110, 15-26.

West, M. J., King, A. P., \& Freeberg, T. M. (1997). Building a social agenda for birdsong. In C. T. Snowdon \& M. Hausberger (Eds.), Social influences on vocal development (pp. 41-56). Cambridge, England: Cambridge University Press.

West, M. J., King, A. P. \& White, D. J. (in press). Discovering culture in birds: The role of learning and development.In F. B. M. DeWaal \& P. L. Tyack (Eds.), Animal social intelligence and complexity. Cambridge, MA: Harvard University Press.

West, M. J., White, D. J., \& King, A. P. (in press). Female brown-headed cowbirds' (Molothrus ater) organization and behaviour reflects male social dynamics. Animal Behaviour.

White, D. J., King, A. P., Cole, A., \& West, M. J. (2002). Opening the social gateway: Vocal and social sensitivities in brown-headed cowbirds (Molothrus ater). Ethology, 108, 23-37.

White, D. J., King, A. P., \& Duncan, S. D. (2002). Voice recognition technology is a tool for behavioral research. Behavior Research Methods, instruments, and Computers, 34, 1-5.

White, D. J., King, A. P., \&West, M. J. (in press-a). Facultative development of courtship and communication in cowbirds, Molothrus ater. Behavioral Ecology.

White, D. J., King, A. P., \&West, M. J. (in press-b). Presence of juvenile males impacts adult male social development in cowbirds (Molothrus ater). Behaviour.

Wynne-Edwards, V. C. (1962). Animal dispersion in relation to social behavior. Edinburgh, Scotland: Oliver \& Boyd.

Received May 14, 2001

Revision received November 28, 2001

Accepted January 30, 2002 